\title{
Educational problems of Syrian refugee students
}

\author{
Problemas educativos de los estudiantes refugiados sirios
}

Received: October 12, 2020

\begin{abstract}
This qualitative study tries to explore the problems faced by the Syrian Refugee primary school students who immigrated to the Kurdistan Region of Iraq (KRI) with their friends in the educational settings and the solutions to those problems from the perspectives of those students. The qualitative data were collected through semistructural interviews from the 15 Syrian Students in different grades. The data were analyzed by the content analysis and descriptive analysis technique in NVivo 12. It was found out that the students were exposed the mostly " violence/ hit", " be disturbed" and "ignorance" by their classmates. The refugee students think that those problems can be solved by their teachers, principles, and families. Some of the students said that they could solve the problems they faced by " staying away" or by "fighting with those who behave badly." Based on the interview decoding, all the Syrian refugee students expect " not to exclude them", "respect" and "love". According to these results, providing social-psychological support, language teaching programs, and teaching tolerance to local students would help to solve the immigrant students' problems having with their friends at school.
\end{abstract}

Keywords: classmates, primary school, problem, refugee, student, solutions.

\section{Introduction}

Today, developments in technology, the internet, communication, and transportation networks have brought the globalization phenomenon of the world. In addition to these, education, health, wars, and cultural reasons caused people to migrate. Undoubtedly, this migration movement
Accepted: December 18, 2020

\author{
Written by: \\ Sevgi Celik ${ }^{17}$ \\ https://orcid.org/0000-0001-5214-8347
}

\section{Resumen}

Este estudio cualitativo intenta explorar los problemas que enfrentan los estudiantes de escuela primaria refugiados sirios que emigraron a la región del Kurdistán de Irak (KRI) con sus amigos en los entornos educativos y las soluciones de esos problemas desde la perspectiva de esos estudiantes. Los datos cualitativos se recopilaron mediante entrevistas semiestructúrales de los 15 estudiantes sirios de diferentes grados. Los datos fueron analizados mediante la técnica de análisis de contenido y análisis descriptivo en NVivo 12. Se encontró que los estudiantes fueron expuestos mayoritariamente a " violencia / golpe ", " ser molestado " e " ignorancia " por parte de sus compañeros. Los estudiantes refugiados piensan que esos problemas pueden ser resueltos por sus maestros, principios y familias. Algunos de los estudiantes dijeron que podrían resolver los problemas que enfrentaban "manteniéndose alejados" o "peleando con los que se comportan mal". Según la decodificación de la entrevista, todos los estudiantes refugiados sirios esperan "no excluir ellos ", " respeto " y " amor ". Según estos resultados, brindar apoyo psicológico social, programas de enseñanza de idiomas y enseñar tolerancia a los estudiantes locales ayudaría a resolver los problemas de los estudiantes inmigrantes con sus amigos en la escuela.

Palabras claves: compañeros de clase, escuela primaria, problema, refugiado, estudiante, soluciones.

has brought social, economic, cultural, and educational problems. It can be said that families, especially children, who migrated due to wars were negatively affected by this phenomenon in all dimensions throughout their lives. According to United Nations data (UNHCR, 2019) 79.5

\footnotetext{
${ }^{17}$ Faculty of Education, Tishk International University.
} 
million forcibly displaced people in the world, 26 million of those are refugees; 45.7 million internally displaced persons; 4.2 million refugees have been identified. These figures are just a part of global migration movement statistics.

Almost every country in the world receives immigration. Especially in the second half of the twentieth century, mass population movements took place, and the immigrant population increased rapidly in the last 50 years. As a matter of fact, according to the data of the United Nations, if the migration movement continues to increase with the speed of the last 20 years, the number of international migrants in the world is expected to reach 405 million in 2050. In Kurdistan Region of Iraq (KRI), which opened its doors to immigrants as a geographical location, protect those who need space, and is a region that has ownership of the long tradition of immigration respected by the public world (Warda and Almaffraji 2020). KRI is home to many refugees. A total of 252,983 Syrian refugees, 44,486 refugees from other countries, and 47,515 stateless refugees are currently living mostly in Erbil $(122,666)$ Dahuk $(84,188)$, and Sulaymaniyah (31,313). There are also 1.3 million internally displaced people living in KRI (UNHCR, 2020). These refugees are supported by the United Nations High Commissioner for Refugees, alongside other organizations, to ensure that their most basic needs are met. However, securing these resources is still a challenge. Examples of the resources that are still required include food, shelter, medical treatment, and education.

Many of these refugees are school-age children who are missing out on education, childrotection, mental health treatment, and other basic services. Many of them have gone through the tragedy of losing one or both parents, their homes, and their schools, and they need much more support to ensure that they can survive, now and in the future. The fact that these children are missing out on basic education is hugely concerning. Throughout history, education has been one of the most important ways of surviving hardship and securing a promising future. Without education, these children will remain uneducated and jobless. This has severe implications not only for them and their families but for society and the economy.

Therefore, it can be said that the immigration and schooling rate from Syria is mostly in Refugee Camps located in Erbil. Families coming through immigration need to carry out some official procedures to enroll their children in schools in these cities. The children don't need to be able to speak Kurdish or Arabic before enrolling in school. Children's right to access school cannot be denied on the grounds since they cannot speak Kurdish (Naidoo, 2012). Some of these children, who are included in the education process without the requirement to speak Kurdish, benefit from kindergarten education, and then continue to primary school.

For the 32,198 registered refugee school children (Crisis and Centre, 2019) whose lives have been disrupted and changed in this way, school is often the first place where they begin to regain their normality. School means order, security, peace, and friendship for children. Regardless of their nationality or legal status or the situation of their parents, children are entitled to academic and curricular activities through school that will enable them to develop themselves (DrydenPeterson, 2017b). Primary school, where basic knowledge and skills are acquired, is a nice and fun opportunity for foreign students to hold on to life again and get rid of the negativities they have experienced. Moreover, having an academic expectation from them about the lessons can be difficult to deal with, especially for a student who does not know the language of the country. For those thousands of refugee children, whose lives have been disrupted and changed in this way, school is often the first place where they begin to regain their normality. However, it is very difficult to adapt to school, class, teachers and friends, especially for these children who migrated due to negative reasons such as war. Moreover, having an academic expectation from them about the lessons can be difficult to deal with, especially for a student who does not know the language of the country.

This study aims to explore the problems refugee students having with their friends in terms of social adaptation at elementary school and propose solutions at a first glance. The study also sought an explanation as to why local students showing disrespectful behaviors to their refugee mates despite the immigrant students want to have a safe environment in their school setting.

\section{Theoretical framework}

The immigrant wants to carry the identity, selfidentity, psychological disposition, satisfaction, and well-being of his old culture to the new cultural system (Taylor and Sidhu, 2012). However, not being able to achieve this and being deprived of the social support elements, it may cause pathologically some affective and cognitive problems in the individual 


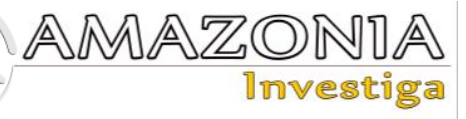

(McCarthy, 2018). On the other hand, it is easier for refugee students, who are in the process of adaptation to a new country, to benefit from education efficiently, to put aside their negative experiences and to hold on to life, to feel positive feelings about their new country of origin with a positive teacher attitude. In primary school, where first experiences, learning, and attitudes are formed, classroom teachers' approach to refugee students is of great importance (Maadad and Matthews, 2018).In addition to their teachers, groups of friends are also very important for these students to adapt to their environment and gain efficiency from their education.

School means order, security, peace, and friendship for children. Regardless of their nationality or legal status or the situation of their parents, children are entitled to academic and curricular activities through school that will enable them to develop themselves (Pastoor, 2014)

According to (Morrice et al, 2019) Syrian students in particular and foreign students in general experience problems in adapting to school due to their different ethnic and cultural backgrounds. Children often experience language and communication problems in educational and social settings. Negative experiences such as anxiety, trauma, insecurity, poor health conditions, depression, and overarousal during the war and migration process negatively affect their cognitive processes and reduce their academic success. Besides, families cannot adequately support children's education due to difficult living conditions (Aydin and Kaya, 2017; Naidoo, 2012; Yassen, 2017). Thus, the desire of students from different countries and different cultures to provide equal education in primary schools within the scope of compulsory education brings the multicultural education approach to the agenda.

Multicultural education; is an educational approach that aims to provide equal educational opportunities for students from different races, social groups, and ethnic backgrounds, to change and restructure the school environment. According to Fruja Amthor and Roxas (Amthor and Roxas, 2016), multicultural education is based on the principles of democracy, equality, and justice. Therefore, the involvement of students from various nationalities in the educational process with the social and educational facilities of the school creates a cultural interaction.
In the multicultural education approach involving international students, it is necessary to mention the concept of culture shock, which explains the difficulties experienced by individuals from different cultures and living in a foreign country. The concept of culture shock is used to describe the state of anxiety and distress caused by not knowing what to do in a new culture (Sheikh and Anderson, 2018). Inevitably, discomfort caused by being in a different country and a different culture causes emotional and social problems in the person. Conditions and symptoms that cause cultural shock; in the new culture of the individual may vary depending on the level of psychological resilience and spiritual bases. Depending on this situation, it is predicted that individuals who are forced to migrate and who are exposed to traumatic experiences before, during, and after migration will experience many psychological and socio-cultural problems in the process of adapting to the new culture (Villalba, 2009). The greater the similarity between the two cultures, the less culture shock an individual will experience. However, here, it is necessary to consider the negative events that the person experienced as the reason for leaving his country. The attitude, tolerance, hospitality, and similarity of cultural elements of the country of origin towards foreigners can reduce the difficulties experienced.

In their research, Oh and Van Der Stouwe (2008) stated that in terms of the refugee phenomenon, an issue closely related to the culture of tolerance and peace is social integration. Regardless of which society is immigrated, one of the main goals of that society is the harmony of immigrants, their involvement in social integration, and thus the continuation of community life peacefully and healthily. Thus, the immigrant can assimilate the values of the society to which he migrated while building a new identity without losing his values (Bretherton 2004). Realizing all these requires both a time consuming and difficult process. Besides, Villalba (2009) stated that in multicultural environments caused by the international migration movement, it is a necessity to be able to communicate with each other healthily, to create effective and efficient cooperation, to ensure cultural harmony, and to prevent conflicts. Fruja Amthor and Roxas (2016) mentioned five main approaches to multicultural education: Education that focuses on equalizing educational opportunities of culturally different students aims to understand cultural differences, protect cultural pluralism, help students to work in different cultures and improve competence in multiple systems. 
Therefore, it can be thought that with multicultural education, problems related to social cohesion and communication at school will decrease with an education that decreases prejudices and provides equal opportunities in the education of international students.

The mutual cohesion approach needs to be supported through inclusive practices (Block et al, 2014) and combating racism, discrimination, and xenophobia towards refugees. As Pastoor (2017) indicated educational environments and school climate should be friendly, positive, and supportive for both students and families It is possible that individuals who migrate internationally and who are in minority status in the country they settle in, focus on the dominant local culture, their own culture, both or not to either. When evaluated in terms of these options, cultural adaptation is defined as the adaptation and acquisition of immigrant individuals to dominant cultural norms in a sociocultural sense (Yohani, 2013). On the other hand, students' social/affective skills are also influential factors in the process of adaptation to their environment.

Socialization is a social concept that is related to the society in which an individual life. Every society expects individuals to develop certain behaviors for different situations. The individual also realizes himself while learning these behaviors. While some individuals are extroverted in this process, some individuals may have difficulty expressing themselves. Social/emotional skill is related to the individual's self-knowledge and ability to express himself correctly and then to strengthen his ties with those around him (Tangen and Beutel, 2017). The primary school period is an important period in which peer relationships and social skills development in the playgroups. For this reason, healthy communication with peers in this process can affect both the development of social/emotional skills of the child and healthy personality development. The children of families who have to migrate from their countries for various reasons - especially at the basic education level - experience various problems such as adaptation to their friends and teachers, language and communication, not being able to understand the lessons and not being successful. When the studies conducted both abroad and in the country were examined (Bačáková and Closs, 2013; Goings, Bristol and Walker, 2018; Vergou, 2019; Watkins and Zyck, 2014; De Wit and Altbach, 2017) it was determined that foreign students had various problems. However, it is stated that, in general, domestic research is mostly aimed at Syrians, and problems are determined by the perspectives of teachers or administrators; Studies abroad are seen to be related to education and adaptation problems (Aydin and Kaya, 2017; Bačáková and Closs, 2013; Bretherton, 2004; Dryden-Peterson, 2016; McPherson, 2010; Naidoo, 2012; Oh and Van Der Stouwe, 2008; Vergou, 2019; De Wit and Altbach, 2017);

In this context, the adaptation problems of refugee elementary school students, who had to immigrate to KRI, and the solutions to these problems, were aimed to examined through indepth qualitative research methodology. The results to be obtained from such research will guide universities that play a role in training elementary school teachers who will develop more fundamentally what can be done for immigrant students, and the Ministry of National Education organizing in-service training and teacher practices. Based on this, the problem statement of the study is; What are the problems and the solutions that the refugee elementary school are students having with their friends at school?

\section{Research questions}

- What are the problems that primary school students who came through migration have with their friends?

- What do the Syrian refugee primary school students think about their relations with their classmates?

- Do the Syrian primary school students think that they can solve the problems they have with their friends?

- In the face of the problems that primary school students have with their friends; what are their expectations from their friends? What do these students think is the solution?

\section{Methodology}

A qualitative research design was used in this study to collect data in the field at the site where the researcher tried to explore, understand and interpret the refugee primary school students' difficulties faced with their local friends in terms of adaptation, and social cohesion. The qualitative research design was suitable for this research to understand the meaning of the examples given by the participants and to reveal their problems 


\section{amsomen \\ Participants}

The research was conducted in a public school in Zanco district of Erbil province as a convenient sample in the fall semester of the 2019-2020 academic year. The appropriate sampling method (convenience / accidental/incidental sampling), which is also known as accidental or favorable sampling, was used to prevent loss of time,

Table 1.

Demographic characteristics of the participants.

\begin{tabular}{|c|c|c|c|c|c|}
\hline Student & Sex & Age & Grade & Siblings & $\begin{array}{l}\text { Duration in } \\
\text { Region }\end{array}$ \\
\hline $\mathrm{S} 1$ & $\mathrm{M}$ & 8 & $2^{\text {nd }}$ Grade & 3 & 1 \\
\hline $\mathrm{S} 2$ & $\mathrm{~F}$ & 8 & $2^{\text {nd }}$ Grade & 3 & 1 \\
\hline S3 & M & 9 & $3^{\text {rd }}$ Grade & 3 & 2 \\
\hline S4 & M & 9 & 2nd Grade & 4 & 4 \\
\hline S5 & $\mathrm{F}$ & 11 & $4^{\text {th }}$ Grade & 3 & 5 \\
\hline S6 & M & 9 & 2nd Grade & 3 & 4 \\
\hline S7 & $\mathrm{F}$ & 10 & $4^{\text {th }}$ Grade & 2 & 1 \\
\hline S8 & $\mathrm{F}$ & 10 & $4^{\text {th }}$ Grade & 4 & 4 \\
\hline S9 & $\mathrm{F}$ & 9 & $3^{\text {rd }}$ Grade & 2 & 3 \\
\hline S10 & M & 8 & 2nd Grade & 2 & 4 \\
\hline S11 & M & 8 & 2nd Grade & 4 & 2 \\
\hline $\mathrm{S} 12$ & M & 7 & $1^{\text {st }}$ Grade & 3 & 2 \\
\hline S13 & M & 8 & 2nd Grade & 1 & 2 \\
\hline S14 & $\mathrm{F}$ & 8 & 2nd Grade & 1 & 1 \\
\hline S15 & $\mathrm{F}$ & 9 & $3^{\text {rd }}$ Grade & 2 & 2 \\
\hline
\end{tabular}

\section{Data Collection}

To find out the demographic characteristics of the students, a Personal Information Form consisting of 6 questions prepared by the researcher was delivered to the participants. After collecting the demographic information of the students, an interview form was used to figure out the students' problems and their thoughts on the solution. While preparing this form, the literature was reviewed, and draft questions were created by evaluating the social problems of immigrant students with their friends. During the process of question preparation, the ideas of two experts, a class teacher, and psychological counseling and guidance specialist, were requested to make the interview questions more reliable. In line with these views, the interview form was finalized. A pre-application was made before the application and it was seen that the questions were understood. Before the interviews were made with the students, a meeting schedule was created by obtaining parents' permission, and after that interview was conducted. The questions in the form are as follows: 1) Have you ever had problems with your friends? 2) What problems did you encounter? 3) Who do you think can solve your friends' problems? 4) How money, and labor. In this study, the researcher worked on the most accessible and maximum saving situation samples (Creswell, J. W., \& Clark, 2017). Among the 19 refugee students who attend this school, 15 students participated in this study with parental permission. The demographic characteristics of the students in the study group are shown in Table 1. do you solve the problems you have with your friends? 5) What do you expect from your friend with whom you have a problem? 6) What do you think the solution is? The data were collected at the students' schools. A preliminary interview was held with the students to make the interview very clear by giving brief information about the research. Later, the meeting schedule and location were determined with the school administration. Between December 3-13, 2019, the form was administered by the researcher with a one-to-one interview with the students. It took 20-25 minutes for each of the forms to be completed. The literate students read the form themselves and wrote their answers. A Syrian student who knew Kurdish and Arabic well worked as a translator for the other students who could not fully understand English and Sorani Kurdish. The researcher recorded the interview and decode them by using NVIVO 11.

\section{Data Analyses}

Content analysis and descriptive analysis were used to analyze the research data. Relations and concepts were tried to be determined with the method of content analysis. Descriptive analysis is an approach that enables the interpretation and 
explanation of the data obtained under the themes, examining the cause-effect relationships, and reaching the result. Besides, this analysis technique allows the data to be presented by considering the research questions (Foster 1987). After the forms were collected from the students, they were numbered, and the answers given to each question were read separately by the researcher. The descriptions obtained from the forms were coded and the categories were determined. In coding and categorization, the researcher first identified separate categories and ensured consistency. Later, she settled the disagreements in naming the categories that came together, provided the matches, and reached a common decision. In the study, code names such as S1, S2, S3 were used instead of the real names of the participants. The families of the students were contacted, information was given about the research, and the students were included in the study voluntarily.

Validity and Reliability Studies
The subjects with "consensus" and "disagreement" among the researchers were determined. The coder reliability was found to be $98 \%$ with the formula of Consensus / (Disagreement + Consensus) x 100 put forward by (McCarthy, 2018), and it was concluded that the specified categories were consistent. Direct quotations from student expressions are included to ensure clarity.

\section{Results and discussion}

This section includes findings based on research questions. Each theme is presented as a table, and the descriptions of the categories are included in the tables and under the tables. Students' views regarding the problems they have with their friends

The first question of the research is "Have you ever had problems with your friends? What problems did you encounter?" The answers to the question are shown in Table 2.

Table 2.

The answers to 'Have you ever had problems with your friends? What problems did you encounter?",

\begin{tabular}{lll}
\hline categories & Sub-categories & frequency \\
\hline Yes & Violence / push / hit & $\mathbf{6}$ \\
& Joking/acting badly & $\mathbf{5}$ \\
& Be disturbed & $\mathbf{4}$ \\
Cursing / insulting & $\mathbf{3}$ \\
& Physical harassment & $\mathbf{2}$ \\
Ignorance & $\mathbf{2}$ \\
No & Shout / Get Angry & $\mathbf{1}$ \\
Total & & $\mathbf{3}$ \\
\hline
\end{tabular}

When Table 2 is examined, it can be understood that the participant is mostly exposed "violence / pushing / hitting", then "making fun of/abusing", "being disturbed" and "cursing/insulting", "physical harassment", "ignorance" and least "yelling/angry" behaviors by their local class friends. Three students stated that they did not have any problems with their friends.

Some student stated that they were subjected to violence by their friends are as follows: "Every day I have problems with my friends at every break. They say goods, swear and hit them. They make fun of my name. (S7) "," They make hand gestures. (S9) "," They hit my head, interfere, disturb, push and shout. (T14)", "Some of them are teasing. (T10)" and "My friends mistreat me and get angry with me (T2)" The students also reported the social problems they experienced with their friends and the behaviors they were exposed to.
Most of the students indicated that their friends made fun of and behaved badly in different ways: "They disturb me in class, I am beaten, they make fun of me (T1)", "They make fun of me and disturb me. (S13)" A student said that he was swearer and insulted: "My friends are cursing, pushing, hitting. (T3)", another student said that he was excluded with the statement "My friends do not let me in their games, they always exclude me (T4)".

\section{Students' Views Regarding Who Can Solve Their Problems with Their Friends}

The second question of the research is "Who do you think can solve your problems with your friends?" The answers to the question are given in Table 3. 
Table 3.

Answers to the question "Who do you think can solve your problems with your friends?"

\begin{tabular}{ll}
\hline Categories & Frequency \\
\hline Teachers & $\mathbf{6}$ \\
Myself & $\mathbf{4}$ \\
Principle & $\mathbf{4}$ \\
No one & $\mathbf{2}$ \\
My family & $\mathbf{1}$ \\
Total & 17 \\
\hline
\end{tabular}

When Table 3 is examined, it is seen that the students think that the problems they encounter with their friends can be solved mostly by their teachers and in the second place they think that the principal can solve them. Fewer of the participants think that no one can solve the problem they have with their friends, and at least their families can.
Students' views on how to solve the problems they have with their friends

Below are the answers given by the students about how they can solve the problems they have with their friends in Table 4.

Table 4.

Answers to the question "How can you solve the problems you have with your friends?"

\begin{tabular}{ll}
\hline Categories & Frequency \\
\hline Speak with the teachers & 6 \\
By doing nothing & 4 \\
I speak with my friends by myself & 3 \\
I hit & 1 \\
I tell my family & 1 \\
I stay away & 1 \\
Total & 16 \\
\hline
\end{tabular}

When Table 4 is examined, the majority of the participants stated that they could achieve the solution by "talking to the teacher", less by "doing nothing", "by speaking/warning myself", at least by "hitting", "telling the family" or "avoiding" from that friend.

One of the students said, "I tell my mother, if my mother does not interfere then I talk to the teacher (S3)"'. Similar to this expression" I tell the teacher (S11) "and" I try to get the teacher to talk to them (S7)'" express their search for help for a solution. The student coded S14 stated that he could not solve the problem with his statement: "When I had a problem with my friend, I told my teacher, and when he said he cannot not do anything, my problem remained."
Most of these students directly stated that they did nothing when they had a problem with their friends: "I do nothing (T9)", "I stay silent (T8)". First of all, some expressions of the students who directly contacted and tried to solve the problem are as follows: "I warned myself (T13)", "I spoke myself, I told the teacher (T4)", similarly another student said "I warned, I told the teacher (T1)". The answer of a student who stated that he was trying to solve is quite thought-provoking: "I try to run away from everyone and beat those who bother me. (T15)",

Students' expectations from their friends for their problems and their views regarding the solutions they think 
Table 5.

Shows the expectations of the students who have problems with their friends and the answers for the solutions they think.

\begin{tabular}{ll}
\hline Categories & Frequency \\
\hline Being nice / not excluding / being friends & 8 \\
Respect & 2 \\
Love & 2 \\
Not kidding / no hitting & 2 \\
Changing school or class & 2 \\
Stay away & 1 \\
Hitting & 1 \\
Total & 18 \\
\hline
\end{tabular}

In Table 5, it is seen that most of the participant students think that "being nice/ not excluding/being friendly to $m e^{\prime \prime}$ can be a solution to their problems. Yet, less of them think that "showing respect" and "love" "not making fun / not hitting" and "changing school/class" can solve their problems. The least of the students, on the other hand, see "keeping away" and "hitting" as a solution. Below are examples of participant students' expectations from their friends as a solution from their expressions.

Many of these students are expecting treated well; "I want my friends to be nice to me. (S10)", "I want my friends to treat me kindly, respectfully and love me. (S3)", "I want my friends to behave nicely to me as I treated them (S14) ". The students, who thought that the problem would be solved if their friends stopped making fun of them, expressed their thoughts with the expressions "not to make fun of me and be respectful (S13)" and "Not fooling around and getting shot can solve the problem (S7)".

Two participating students considered leaving school or class as a solution; "I want to go to another school where the principal says treat children well, I want my friends to treat me well, to be my friends. (S8)" and "I want to be sent to another class; I want me to be treated well. (S9)." Another student said, "I want to be taken into games, not to be excluded, not to be seen as an enemy (S4)" he answered as expressing his dreams rather than a solution.

Another student said that the solution to the problem is to stay away from them, and if this does not happen, he resorted to violence: " $A t$ least I also beat those who bothered me. (S15)',

\section{Discussion}

In this section, the results, discussions, and suggestions about the problems that the participant students have with their friends and their opinions about the solution are included.

Based on the findings obtained;

- Participating students with their friends were mostly exposed to "violent / pushing / hitting", then "making fun of / abusing", "being disturbed" and "cursing / insulting", "gesturing / harassment", "exclusion" and at least "shouting.

- Participant students thought that the teacher himself or the principal could solve the problems they encountered with their friends; fewer think that no one can solve the problem they have with their friends, and at least their family can.

- The majority of the participating students thought they could achieve the solution by "talking to the teacher", "doing nothing", "by speaking/warning their own", and less by "hitting."Some of the students think the solution to the problem is that "telling the family" or "staying away" from those friends.

- It has been found out that most of the participant students think that if "their friends behave well and not to exclude them", can be a solution. They also stated that showing "respect" and "love" will establish a good friendship.

Karam, Monaghan, and Yoder (2017); Matthews (2008) and; Morrice et al. (2019); (Maadad and Matthews 2018; Vergou 2019; Watkins and Zyck 2014)stated that refugee students have communication problems, according to teachers' opinions. Under the heading of communication problems, it was determined that these students experienced isolation from the learning-teaching environment, inability to understand/perceive concepts, as well as vital exclusion, social 


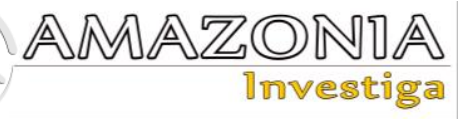

exclusion, and verbal communication deficiency. The given messages cannot be understood by refugee students because they have language problems; refugee students are exposed to exclusion as a result of false judgments and negative statements. Moreover, in the study, it was found out that student's ignorance from the classroom reveals adaptation and attitude problems. These results overlap with the problems arising from exclusion and communication in the present study.

Matthews (2008) identified the social problems experienced by foreign students as social traditions, making friends, relations with the opposite sex, and acceptance by social groups. Besides, Mansour (2018) in his research done in Egypt found out that foreign students experience cultural adaptation problems. On the other hand, Dryden-Peterson (2016) stated that foreign students, create a common language through games and communicate with their friends even if they have problems with their friends. Fruja Amthor and Roxas (2016) determined that teachers encounter language and behavioral problems in the education of foreign students.

Yassen (2017) also stated in his research that foreign students experience adaptation problems to school due to their different ethnic and cultural backgrounds. Again, the teachers who participated in this study mentioned fighting and violence as the problem of Kurdish students. In other words, Kurdish students sometimes use violence against foreign students. In the current study, the students' expressing that they were subjected to violence, maltreatment, and insults in their answers is similar to those studies.

Many research indicated that refugee students have language problems in their new countries (McPherson, 2010; Sheikh and Anderson 2018; Warda and Almaffraji, 2020). Dryden-Peterson (2016) found a close relationship between children's English levels and social skills in his research with Chinese refugee children. Therefore, it is possible to comment that the participants who cannot speak Kurdish at a good level reflect this situation on their social skills, communication, and friendship relations.

According to Tosun, Yorulmaz, and Yildiz (2018); one of the main instructional problems faced by classroom teachers with refugee students is that the refugee students do not know the language they live in and during the education process. They try to learn the language rather than the course content. Similarly, Bakali and Wasty (2020) and Taylor and Sidhu (2012) expressed the main problem that refugee preschool students experience at school is the language and the adaptation problem caused by the cultural difference. They also commented that the language problem and inability to communicate with peers lead to behavioral problems over time. In their study, Lems (2020) and Arsal (2019) remarked that perceived discrimination makes the refugee students' sociocultural adjustment more difficult. They declared that as the perceived discrimination level of the students increased, they face more sociocultural adaptation difficulties. In the current study, the fact that the refugee students are facing ignorance in their schools' advocate the findings in different countries mentioned above.

McIntyre and Hall (2020) categorized the problems faced by Syrian refugee school children into three groups as trust, assistance, and communication. It was found that the students did not trust the people around them due to the traumatic events they experienced. They had language and communication problems, and they disrupt their education because of having had difficult economic situations. These findings overlap with the violence that students experience with their friends, exclusion, and language and communication-related problems in the present study. Shamieh, Sawalha, and Madanat (2020) emphasized in their study done with the school administrators, that almost all of the participants observed communication problems mostly with Syrian students. Kostoulas-Makrakis and Makrakis (2020); and De Wal Pastoor (2016) demonstrated that refugee students' illiteracy of the language where they live is the most fundamental adaptation problem in their social and school life, and this situation can cause different problems. DrydenPeterson (2017a) reported that one of the most important problems during the Syrian students' participation process informal education is their adaptation to school. In the present study, all the statements that the participants stated that they are having similar problems with the other immigrant students in the world. Also, Kurdish primary school students are not satisfied with the refugee students and do not want to establish good relations. This negative attitude of Kurdish students suggests that immigration students may naturally affect the cultural shock they faced even more.

The teacher's perspective is very important for the adaptation of foreign students to the school, their friends, and their active participation in the education process. The openness of a teacher to 
communicate, knowing problem-solving strategies, and exhibiting a positive and peaceful attitude will contribute to the solution of many problems in the classroom. The fact that the participant students mostly expect support from the teacher in the solution. The present study reveals the importance of the teacher in the process of problem-solving and refugee students' adaptation from the perspective of the students. One of the participants of this study said, "When I had a problem with my friend, I told my teacher, when he said he cannot do anything, my problem remained, and I could not solve the problem. (S14)" This statement expresses that this student is not supported by the teacher. The attitude and support of teachers to these students is an important issue that needs attention. One of the common research findings in their meta-analysis studies of Wilkinson and Kaukko (2020) is that teachers have pedagogical deficiencies in approaching these children. The education of foreign students, particularly those of war-torn asylum seekers, is a special field and their training requires special effort from teachers. Sunata and Özdemir (2020) noted that Syrian students cannot fully express themselves to their friends, staff, and teachers. In the current study, the answer "not doing anything" shows similarities in solving the problems that students have with their friends. The finding of DrydenPeterson et al. (2019) is that pre-school refugee children prefer to watch quietly in a corner without participating in the activities in the classroom and stay away from the activities, even if they are fun. Four teachers participating in the study of Şimşir and Dilmaç (2018) mentioned that Turkish students were unwilling to communicate with foreign students.

In the current study, it is important to know that the participant students expect good behavior from their friends and ask for respect and love, as it makes them think that they do not receive this interest. It can be stated that insulting those students also damages respect and love, as well as healthy communication. Again, in the same study, one of the teachers stated that "mostly Syrian children talk to each other". Maadad and Matthews (2018) on the other hand, noted that they observed that Syrian students preferred behaviors aimed at gaining approval passively in the society during the social acceptance process. Also, they stated that the refugee students tried to be accepted and adopted despite being in difficult living conditions, as well as avoiding conditions that would force them and prefer to remain silent. Similar to the present study, what is stated in both studies coincides with the findings that these children stay away from Kurdish children with whom they have problems, stay silent and do nothing. In their research, Sunata and Abdulla (2020) discovered that the Syrian refugee students coped with the challenges of being a refugee in Turkey in that they give examples of some religious, familial, and social solutions. Speaking of religion as a spiritual element that supports them, students put forward prayers such as praying, reading the Qur'an, and praying to solve their problems. They also stated that getting support from their families was good. It was figured out that the students also saw some moral or personal values as a solution in dealing with difficulties. For example, being calm, being courageous, being patient is among the solutions frequently mentioned by students. In this study, some students expressed the helpfulness of the people around them, and making friends help them to cope with problems. Bakali and Wasty (2020) identified language problems, teachers' pedagogical deficiencies, and lack of communication in their study on Syrian students in primary and secondary schools. In this study it was found that Syrian students were prone to violence; even their games contain violence and they show behaviors that physically harm each other. In the study of Şimşir and Dilmaç (2018), the teachers who participated in the research mentioned the problems of fighting and violence of foreign students. These results coincide with the statements of the students who stated that they can solve the problem by shooting, even if a little. The tendency of aggression in Syrian children can be associated with the problems of violence, insult, exclusion, and maltreatment in the school environment, after witnessing war and negativity. Similar to these studies, it can be thought that failure to solve the problems in communication, social relations, exclusion, and violence realized in the present study may cause bigger problems in the long run. In light of the results of this study, the opinions of the students about the problems they had with their friends are violence, insulting, make fun of, and exclusion. On the other hand, the refugee students propose solutions to their problems such as asking the teacher to warn their friends, talking to friends, staying away and resorting to violence in the form.

\section{Conclusions}

Social support and language teaching programs can be applied to primary school students who come through immigration. Guidance activities can be provided to develop the problem-solving skills of foreign students against various problems that may occur in the school environment. Educational activities including 


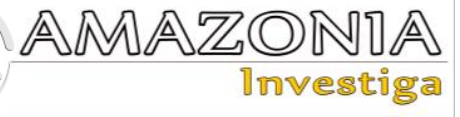

families can be planned for foreign students regarding the problems they experience. It can be ensured that teachers, principals, parents, and administrators control the situation and take the necessary precautions so that refugee students are not excluded by their friends. Within the scope of the guidance, all students can be given communication seminars with students from different cultures so that refugee students are not exposed to ignorance from peer bullying by their friends. In-service training can be organized for teachers regarding the education and social adaptation of foreign students. Psychological counseling and guidance activities can be organized in schools related to social adaptation and multicultural education, and students can be educated within a certain program.

\section{Suggestions for Researchers}

Research can be conducted on the problems experienced by middle school, high school, and university students and their solutions.

Research can be conducted on the problems of branch teachers, university lecturers, teacher candidates, and foreign students.

\section{References}

Amthor, R, F., and Roxas, K. (2016). "Multicultural Education and Newcomer Youth: Re-Imagining a More Inclusive Vision for Immigrant and Refugee Students." Educational Studies, 52(2), pp 155-76. Doi: 10.1080/00131946.2016.1142992.

Arsal, Z. (2019). "Critical Multicultural Education and Preservice Teachers' Multicultural Attitudes." Journal for Multicultural Education, 13(1), pp 106-18. doi: 10.1108/JME-10-2017-0059.

Aydin, H. and Yeliz K. (2017). "The Educational Needs of and Barriers Faced by Syrian Refugee Students in Turkey: A Qualitative Case Study." Intercultural Education, 28(5), pp 456-73. doi: 10.1080/14675986.2017.1336373.

Bačáková, M. and Closs, A. (2013). "Continuing Professional Development (CPD) as a Means to Reducing Barriers to Inclusive Education: Research Study of the Education of Refugee Children in the Czech Republic." European Journal of Special Needs Education, 28(2), pp 203-16. doi: 10.1080/08856257.2013.778108.

Bakali, N. and Wasty, S. (2020). "Identity, Social Mobility, and Trauma: Post-Conflict Educational Realities for Survivors of the Rohingya Genocide." Religions, 11(5). doi: 10.3390/rel11050241.
Block, K., Cross, S., Riggs, E. and Gibbs, L. (2014). "Supporting Schools to Create an Inclusive Environment for Refugee Students." International Journal of Inclusive Education, 18(12), pp 1337-55. doi: 10.1080/13603116.2014.899636.

Bretherton, L. (2004). "Tolerance, Education and Hospitality: A Theological Proposal." Studies in Christian Ethics 17(1), pp 80-103. doi: 10.1177/095394680401700106.

Creswell, J. W., \& Clark, V. L. P. (2017). 'Designing and Conducting Mixed Methods Research.' Sage publications.

Crisis, Joint, and Coordination Centre. (2019). "Situational Report: The Education for Syrian Refugee Students in Kurdistan Region of Iraq.", Report No. (24), 27 March 2019.

De Wit, H., and Altbach, P. (2017). "The Syrian Refugee Crisis and Higher Education." International Higher Education, (84), p 9. doi: 10.6017/ihe.2016.84.9109.

Dryden-Peterson, S. (2016). "Refugee Education in Countries of First Asylum: Breaking Open the Black Box of Pre-Resettlement Experiences." Theory and Research in Education, 14(2), pp 131-48. Doi: 10.1177/1477878515622703.

Dryden-Peterson, S. (2017a). "Refugee Education: Education for an Unknowable Future." Curriculum Inquiry, 47(1). Doi: 10.1080/03626784.2016.1255935.

Dryden-Peterson, S. (2017b). "Refugee Education." Educational Researcher, 45(9), pp 473-82. Doi: 10.3102/0013189x16683398.

Dryden-Peterson, S, Adelman, E., Bellino, M.J. and Chopra, V. (2019). "The Purposes of Refugee Education: Policy and Practice of Including Refugees in National Education Systems." Sociology of Education, 92(4). Doi: 10.1177/0038040719863054.

Foster, L. (1987). "Issues in Multicultural Education: Pre-Service Teacher Education." South Pacific Journal of Teacher Education, 15(1), pp 11-28. Doi: 10.1080/0311213870150103.

Goings, R.B., Bristol, T.J., and Walker, L.J. (2018). "Exploring the Transition Experiences of One Black Male Refugee Pre-Service Teacher at a HBCU." Journal for Multicultural Education, 12(2), pp 126-43. Doi: 10.1108/JME-01-20170004.

Karam, F.J., Monaghan, C. and Yoder, P.J. (2017). 'The Students Do Not Know Why They Are Here': Education Decision-Making for Syrian Refugees." Globalisation, Societies and Education, 15(4), pp 448-63. doi: 10.1080/14767724.2016.1222895.

Kostoulas-Makrakis, N. and Makrakis, V. (2020). "Developing Student-Driven Learning Activities to Promote Refugee Quality Education 
through the CARE Methodology." International Journal of Early Years Education, 28(2). doi: 10.1080/09669760.2020.1765091.

Lems, A. (2020). "Being inside out: The Slippery Slope between Inclusion and Exclusion in a Swiss Educational Project for Unaccompanied Refugee Youth." Journal of Ethnic and Migration Studies, 46(2).

doi:

10.1080/1369183X.2019.1584702.

Maadad, N., and Matthews, Julie (2018). "Schooling Syrian Refugees in Lebanon: Building Hopeful Futures." Educational Review, 72(4), pp 459-474. doi: 10.1080/00131911.2018.1508126.

Mansour, E. (2018). "Profiling Information Needs and Behaviour of Syrian Refugees Displaced to Egypt: An Exploratory Study." Information and Learning Science, 119(3-4), pp 161-82. doi: 10.1108/ILS-08-2017-0088.

Matthews, J. (2008). "Schooling and Settlement: Refugee Education in Australia." International Studies in Sociology of Education, 18(1), pp 3145. doi: 10.1080/09620210802195947.

McCarthy, A.T. (2018). "Politics of Refugee Education: Educational Administration of the Syrian Refugee Crisis in Turkey." Journal of Educational Administration and History, 50(3), pp 223-38. doi: 10.1080/00220620.2018.1440541.

McIntyre, J., and Hall, C. (2020). "Barriers to the Inclusion of Refugee and Asylum-Seeking Children in Schools in England." Educational Review, 72(5). doi: 10.1080/00131911.2018.1544115.

McPherson, M. (2010). 'I Integrate, Therefore I Am': Contesting the Normalizing Discourse of Integrationism through Conversations with Refugee Women." Journal of Refugee Studies, 23(4), pp 546-70. doi: 10.1093/jrs/feq040.

Morrice, L., Tip, L.K., Brown, R. and Collyer. M. (2019). "Resettled Refugee Youth and Education: Aspiration and Reality." Journal of Youth Studies, 23(3), pp 1-18. doi: 10.1080/13676261.2019.1612047.

Naidoo, L. (2012). "Refugee Action Support: Crossing Borders in Preparing Pre-Service Teachers for Literacy Teaching in Secondary Schools in Greater Western Sydney." International Journal of Pedagogies and Learning, 7(3), pp. 266-74. doi: 10.5172/ijpl.2012.7.3.266.

Oh, S. A., and Stouwe, M.V.D. (2008). "Education, Diversity, and Inclusion in Burmese Refugee Camps in Thailand." Comparative Education Review, 52(4), pp 589-617. Doi: 10.1086/591299.

Pastoor, L.D.W., and Review, A. (2014). "Annual Review of Comparative and
International Education 2014." iii. doi: 10.1108/s1479-3679_2014_0000025034.

Pastoor, L.D.W. (2017) Reconceptualising refugee education: exploring the diverse learning contexts of unaccompanied young refugees upon resettlement, Intercultural Education, 28(2), pp. 143-164,

DOI: 10.1080/14675986.2017.1295572

Pastoor, L.D.W. (2016). "Rethinking Refugee Education: Principles, Policies and Practice from a European Perspective." International Perspectives on Education and Society 30.

Shamieh, J.M., Sawalha, I.H., and Madanat, H.M. (2020). "Vulnerability and Capacity Assessment for Refugee Education Crises." International Journal of Emerging Markets. doi: 10.1108/IJOEM-04-2019-0321.

Sheikh, M., and Anderson, J.R. (2018). "Acculturation Patterns and Education of Refugees and Asylum Seekers: A Systematic Literature Review." Learning and Individual Differences, 67, pp 22-32. doi: 10.1016/j.lindif.2018.07.003.

Şimşir, Z., and Dilmaç. B. (2018). "Problems Teachers' Face and Solution Proposals in the Schools Where the Foreign Students Are Educated." Elementary Education Online, 17(3), pp. 1719-37. doi: 10.17051/ilkonline.2018.466425.

Sunata, U., and Abdulla, A. (2020). "Lessons from Experiences of Syrian Civil Society in Refugee Education of Turkey." Journal of Immigrant and Refugee Studies, 18(4). doi: 10.1080/15562948.2019.1692984.

Sunata, U., and Özdemir, A.C. (2020). "CSR Implementations in Refugee Education: The Case of Syrians in Turkey." Social Responsibility Journal. doi: 10.1108/SRJ-042020-0145.

Tangen, D., and Beutel, D. (2017). "Pre-Service Teachers' Perceptions of Self as Inclusive Educators." International Journal of Inclusive Education, 21(1), pp 63-72. doi: 10.1080/13603116.2016.1184327.

Taylor, S., and Sidhu, R.K. (2012). "Supporting Refugee Students in Schools: What Constitutes Inclusive Education?" International Journal of Inclusive Education, 16(1), pp 39-56. doi: 10.1080/13603110903560085.

Tosun, A., Yorulmaz, A., and Yildiz, K. (2018). "Education Problems of Refugee Students, Their Expectations from Education and Religious Education: The Case of Eskişehir." Eskişehir Osmangazi University Journal of Social Sciences, 19(1), pp 107-33. doi: 10.17494/ogusbd.457087.

UNHCR. (2019). Cisac Global Report 2019.Recovered from https://reporting.unhcr.org/sites/default/files/gr2 


\section{AMAZONDA \\ 1กvestiำ}

019/pdf/GR2019_English_Full_lowres.pdf\#_ga $=2.161585788 .1593824046 .1612027274$ 1587122799.1608981607

UNHCR. 2020. "Mid-Year Trends 2020." Recovered from

https://www.unhcr.org/5fc504d44.pdf

Vergou, P. (2019). "Living with Difference: Refugee Education and School Segregation Processes in Greece.” Urban Studies, 56(15). doi: 10.1177/0042098019846448.

Villalba, J.A. (2009). “Addressing Immigrant and Refugee Issues in Multicultural Counselor Education." Journal of Professional Counseling: Practice, Theory \& Research, 37(1), pp 1-12. doi: 10.1080/15566382.2009.12033851.

Wachob, Phyllis, Robert S. Williams, Source Tesol Quarterly, and Adult Language Learning. (2014). "Teachers of English to Speakers of Other Languages, Inc . (TESOL) Teaching English to Refugees in Transition: Meeting the Challenges in Cairo , Egypt in Cairo." 44(3), pp 596-605. doi: 10.1016/S0005-7967.
Warda, W. K., \& Almaffraji, H. S. (2020). Refugee Protection: Iraq Country Report (Global Migration: Consequences and Responses - RESPOND Working Paper Series). Uppsala. https://doi.org/10.5281/zenodo.3629142

Watkins, K., and Zyck, S.A. (2014). "Living on Hope, Hoping for Education: The Failed Response to the Syrian Refugee Crisis." Overseas Development Institute (September).

Wilkinson, J., and Kaukko, M. (2020). "Educational Leading as Pedagogical Love: The Case for Refugee Education." International Journal of Leadership in Education, 23(1) doi: 10.1080/13603124.2019.1629492.

Yassen, A. (2017). Durable Solutions for Syrian Refugees in the Kurdistan Region of Iraq. Middle East Research Institute.

Yohani, S. (2013). "Educational Cultural Brokers and the School Adaptation of Refugee Children and Families: Challenges and Opportunities." Journal of International Migration and Integration, 14(1), pp 61-79. doi: 10.1007/s12134-011-0229-x. 